\title{
E-Learning Development Trends in Computer and Engineering Education
}

\author{
http://dx.doi.org/10.3991/ijep.v3i2.2441 \\ James Uhomoibhi ${ }^{1}$ and Margaret Ross ${ }^{2}$ \\ ${ }^{1}$ University of Ulster, Newtownabbey, Northern Ireland, UK \\ ${ }^{2}$ Southampton Solent University, Hampshire, UK
}

\begin{abstract}
E-Learning continues to evolve and to facilitate access to education through both the fully online and blended modes of delivery. This has contributed in no small measure to widening participation in engineering and computing education anytime anywhere. This paper presents the many changes that have taken place in e-learning, the increase in blended learning and remote students, involving regular contacts with their lecturers by use of webcams, Second Life as well as email, teleconferencing and various other technologies. The range of courses and assessment methods will be discussed, such as the MSc course in e-Learning at the University of Ulster and the MSc in Six Sigma at Southampton Solent University. The paper reports on the range of activities of the British Computer Society eLearning Specialist Group and its increasing influence in various countries around the world, both relating to academic training and personal continuous professional development. The increasing gap in the digital divide faced by learners in the technology driven society of the 21 st century calls for creation of new opportunities for continuous education. We note the need to develop new curricula, appropriate pedagogy and tutor professional development in information technology literacy to prepare and help the tutor develop a critical process for implementing new tools and technologies in education. Engineering and computing educators face a lot of challenges in implementing elearning. There must be clear understanding of if, how and when e-learning may be best employed in their courses to maximise learning experience. In the course of developing such a course the system must be fit for purpose. It is crucial that the educator possess the skills for developing the required system. In situation where this is not the case outside assistance could be employed.
\end{abstract}

Index Terms-BCS E-Learning Specialist Group, Blended learning, E-Learning, Using Second Life, Using webconferencing for remote learners.

\section{I INTRODUCTION}

The growth of access to the Internet has made a major effect on the increasing use of e-learning. It is now easier for those who live either remote from a source of education, or those who wish to join a course at a distant college or university, situated beyond their own country. It also provides opportunities for further study for those that are housebound, such as through disability or caring for young children or other family members.

The reduced cost of purchasing technology, and the increased access to Broadband, has aided the increased interest in and use of e-learning. Students nowadays communicate with the lecturers either as one-to-one or as a group, using e-mail or appropriate technologies such as Skype, for the replacement of the face-to-face personal tuition sessions, dealing with individual problems or specific advice of feedback of the students' work.

Other techniques, such as teleconferencing and web conferencing are suitable for small tutorial groups, where discussion of common problems can be considered. These could relate to material already placed on a learning environment for the students. Web conferencing can also be used to deliver new material, using facilities where the students can share access to the lecturer's screen. They can ask questions by raising a virtual hand to obtain the virtual microphone to be able to be heard by the group, or the students can type a question which is either seen by the others or just seen only the lecturer. This replicates the same process as a lecturer making a Power Point presentation to an attending class of students. The only disadvantage is the lack of eye-contact between the lecturer and the students and the ability by the lecturer to interpret the students' body-language. The use of web cameras can assist in this aspect, but it can have, if many of the students are using them, in addition to the presenter, a deterioration in the response time. These techniques also can be used for group work.

Virtual environments are now beginning to be used, not only for students' individual and group projects, but also for lectures and tutorials. Many universities have purchased "Islands" in Second Life or other virtual environments. They have developed virtual university campuses there to provide both study and recreational facilities for the students. Access to these are available on a $24 \times 7$ basis by students anywhere in the world.

\section{THE GROWTH OF BLENDED LEARNING AT SOUTHAMPTON SOLENT UNIVERSITY}

Students have studied remotely for over thirty years for examinations such as leading to the BCS (British Computer Society) professional examinations. Initially packets of work were posted out to the students on a weekly basis and their work was returned to the tutors in the same manner, with telephone calls made to the tutors at pre-set times by the students. With the wider use of e-mail, the distribution of material as attached files, simplified the processes, reduced the time delay and also considerably reduced the problems of lost packets of material. This was particularly a problem for students in parts of Africa, the Far East and South America. The assessments for these courses were by closed book examinations that were scheduled by the BCS at various locations throughout the world. Students participated in these courses from various 
countries including from Nigeria, Tanzania, Canada, Chile, New Zealand, India and Malaysia.

\section{A. BSc (Hons) Professional Computer Studies}

A top-up course was developed, for those remotely based students, to progress from the BCS professional examinations to being able to obtain a degree. This course was run very successfully until 2007, when it became necessary to change to a more modern approach. This course was organised by regular weekly e-mail sending of material to the students [1].

The students were encouraged to communicate with each other, but their preferred choice was often a 1-to-1 with the appropriate lecturer. With the exception of students who did not undertake the regular feedback work, the results were considerably higher than those on comparable courses with full-time attending students. The disadvantage of running such courses was the high impact of their lecturers' time, both in developing and annually up-dating the material, and also in providing regular feedback. Many students also wanted, in addition to the Internet style communication, the reassurance of telephone conversations. Many of these were more about obtaining reassurance about their progress and providing an opportunity for them to discuss their personal problems in so much as it affected their ability to study. The discussion of alternatives and the consequences of these, when a student had serious studying problems, were often the real purpose of those telephone calls. It was felt that the "human voice" provided the support, when necessary, rather than the more impersonal e-mail communication.

The assessments, for each subject, by the students, were a combination, of a work based report and a three hour closed book examination, both of which had to be passed. The students also undertook additional non-assessed work on a weekly basis for which they received feedback. Individual issues were dealt with by the tutors mainly by e-mail, but the students also could telephone the tutors at pre-set times, if they wished, for private discussions.

Optional sessions were arranged at no additional cost, for the students on various Saturdays at Southampton. Some of the students from the UK and Europe took advantage of these as they could utilise the Southampton airport and the mainline train service. The material covered on these optional Saturday sessions were then sent, together with a summary of the discussions, to all the nonattending students.

One of the first students to study successfully to obtain his BSc degree of upper second grade from Southampton Solent University came from Tanzania. He studied using the distance-learning route, only coming to the UK to take his final examinations and to attend the graduation ceremony for his degree. While studying for his degree, he was able to change his job to a more responsible computing role and to become eventually, by the conclusion of the course, the Computer manager in his organisation. This is just one of the successes from studying the elearning way.

The only required attendance for the students was for the examinations and presentations of the students' final project. All of these were arranged within a single week in June, so that the students from overseas could combine this final aspect of their course with a holiday in the UK.

\section{B. MSc Six Sigma course}

Currently there are students, both from the UK and mainland Europe on the part-time Six Sigma Master's course. For each pair of modules on the course, the material was placed on the university's learning environment, together with the report for each module to be completed within a period of twelve weeks [2]. There are two attending weekends, during that period. The Saturday sessions are relevant to the first module whereas the Sunday sessions relate to the other module. There is also regular communication between the lecturers and the students using Web conferencing.

At the start of the course, the students were given, at their first attending session, training in using the Web conferencing facilities. The lecturers arranged various sessions, at times convenient to these students for these sessions. The students usually chose the evenings at the weekends. The students are able to either speak or type in their questions and comments. These sessions are used both to cover new material (which is subsequently put on the learning environment) and to clarify and assist the students with their assessments. These consist of written reports, together with presentations that the students provide on CD Rom.

These sessions have proved popular with the students. Both the lecturers and the students were provided with microphones. The lecturers were able to run these sessions from their own home. The only problems encountered resulted from initial set-up of the students' equipment. For the first session, a telephone number was also provided to assist the students in overcoming technical problems. Currently, students fly in from Germany and Switzerland to attend the weekend sessions in addition to that resident in the UK.

\section{Use of Learning Environments and Second Life}

Students that attend regularly, either on the full-time or part-time mode, use blended learning on most courses. The learning environment, MyCourse, using Moodle open source software, is used by the lecturers to put on the weekly material to supplement that covered in class. The students are normally expected to access the material, and to undertake some work, often in groups again using the Focus Group facilities of the learning environment, prior to the class. Working in this manner allows the part-time students not to be disadvantaged compared to those attending daily [3].

Students on the fashion course used Second Life as a medium to show their designs and to arrange fashion shows [4]. They can also set up virtual shops to display and "sell" their designs. This approach is seen by the students to be an excellent supplement to their more traditional design of physical items of clothing.

Students on journalism courses are also required to attend these virtual fashion shows and to produce reviews which are similar to those activities they would also undertake in the real world.

Students can continue with their studies leading to PhDs by utilising these techniques. One author, Ross, has doctorial students both in Greece and in the USA. 
PAPER

E-LEARNING DEVELOPMENT TRENDS IN COMPUTER AND ENGINEERING EDUCATION

\section{E-LEARNING AT THE UNIVERSITY OF ULSTER}

The University of Ulster is a modern, dynamic and innovative university that seeks to make a significant contribution to the education, economic and social environment of the region. In the era of present globalization, the university has and continues to increase opportunities for participation in education by enhancing opportunities for access in particular using the vehicles of eLearning and emerging technologies. All faculties have access to the Virtual Campus (CampusOne) and all staff and students have access to the VLE (WebCT). All learning provision (modules) are allocated space in WebCT to which access are granted for individuals as required. A diverse collection of technologies are used across the faculties for online delivery. Some of these include the use Virtual Worlds such as Second Life and of CMC tools such as Skype, Googletalk, Facebook etc and a plethora of tools to facilitate online collaborative learning. In the case of Second Life, the university has an island in Second Life. Some students from one of the Schools were very involved in the development of the university's island and in the collaboratively designing and building products for use in this virtual world.

\section{A. MSc in e-Learning}

The need for teachers to understand e-learning has been addressed by various courses. An example of this is the master's degree course in e-Learning Interactive Teaching Technologies at the University of Ulster. This is designed for teachers and those that administer educational establishments, including those working for educational departments of governments. Students on this course are geographically spread, mainly throughout Northern Ireland. Some students are involved directly in teaching and training using e-learning techniques, however others are more concerned with the technical or the managerial aspects of the use of e-learning. The interaction between the lecturers and the students are by the e-learning environment in addition to e-mail. The students are able to participate in group work using this learning environment. There are a limited amount of face-to-face sessions. The assessments are submitted electronically. The various units are studied, using the Internet, with weekly communications again via the Internet with the other participants on the course and also with the unit leaders. The assessments for the various units and for the final project are also submitted online. The majority of these assessments are directly related, whenever possible to the participant's own work experience and environment. The units on this course include a study of the different systems available, such as Moodle, as well as topics such as the design of elearning material.

In addition to discussion forums via the Internet, telephone and video conferencing are also utilised where appropriate. The successful participants need only come to Belfast if they wish to obtain their Master's degree at the formal ceremony, rather than by post.

The course, jointly delivered by two faculties (Computing and Engineering and Social Sciences), is designed to support those who wish to develop their abilities in online teaching and courseware design within the context of collaborative learning. To achieve this, various delivery formats and media are considered by the eTutors and products and programs are chosen so that they integrate methods of teaching and technology to improve the efficiency and effectiveness of the learning process. Through the combination of the integrated approach to delivery and the use of a rich blend computer mediated communication and resources, the course offers real opportunity to widen participation and to evolve and support the development of professionals in the field of education and training. The course has been developed using an integrated model [5] of online teaching, which offers eLectures, eSeminars and eLearning opportunities for learning programmes development in further and higher education for post-16 students. Online teaching is delivered on the University's CampusOne in fully online mode. To date this course has attracted students from the UK, Ireland, the rest of Europe, Africa, USA etc. WebCT remains the adopted virtual learning environment (VLE). Multimedia has been used for generic information dissemination, for presentation as a tool and as a facilitative mode of learning.

The students are encouraged to consider submitting a paper to a conference or journal, based on their individual assignments and final project, with the help if required of their tutors, to ensure that the paper was of an appropriate standard. The benefit of this would be to increase the confidence of the students, to increase the profile of the students with their employers, and to be of benefit to their $\mathrm{CVs}$, as well as sharing their experience with others. This is an excellent example of an effective e-learning course to develop skills in e-learning.

Graduates from this programme have reported that the course has helped in the orientation of some of their organizations towards organic growth through using and applying the appropriate tools for new and changing tasks. On the VLE, students claim that it has helped them to focus on the need-to-know whilst providing the opportunity to jump to the like-to-know; that their learning is enhanced with the well organized and managed instructional materials and the use of adaptable media has helped to complement their individual learning styles.

\section{E-LEARNING SPECIALIST GROUP}

The BCS e-Learning Specialist Group was established in 2008. It now has over 900 members. Although the majority of these are based in the UK, the membership ranges across about thirty countries from the Far East, Africa to America. Physical meetings are arranged, usually associated with different BCS Branches or local universities. There are regular e-newsletters sent to the membership. The events ranged across topics such as experiences in using particular learning environments, getting started in Second Life, and safety for children with the Internet.

The e-learning Specialist Group also arranges events to raise awareness of the benefits of e-learning, and also to show how to minimise the risks, associated with the use of the Internet and social networking, aimed both at teachers, lecturers and the general public. The ability to gain skills associated with sports by using systems and equipment such as Wii, can be used to introduce children to sports for which there is no available equipment and no local facilities, such as canoeing and skiing. These e-learning facilities also provide a potential opportunity for disabled or elderly users, to be able to experience the various sports that would not be possible in the "real" world. 
The BCS e-Learning Specialist Group holds an annual physical conference, jointly with the BCS Quality Specialist Group. This attracts authors from various countries including in 2010, from Greece, Romania and Nigeria. The proceedings are then published. The range of topics for these conferences cover areas such as the experience in the use of e-learning, in-course development, the tools and methods to assist with web design and in Second Life.

The philosophy is based on the fact that present elearning systems and resources must be developed and made capable to serve the unknown needs of the future, that is, e-learning systems must be fit for purpose. The reference point of the group is the future and is global with needing to fall back on the past. The use of of the web for communication and conduct of business is common at work at home. Web-based education has many advantages for computer and engineering educators over other instructional approaches including the use of packages $[6,7,8,9,10]$. Web-based instructions presents information in a non-linear style and allows students to explore new information through browsing and cross-referencing. It also supports active learning processes. Students play active role in the learning process and acquire knowledge and skills in a more interesting and meaning way. Through the use of the web visualization becomes a reality and 24/7 access to the internet enables education to occur at anytime, anywhere. On the web the learning environment is created accommodating the varying needs of the students. This makes possible true independent and flexible approach to learning.

\section{CONCLUSION}

It is hoped that approaches such as these will assist all who wish to study and to participate in debates relating to promoting e-learning in the future. eLearning as a tool and process is changing the way in which both institutions and learners interact. As a process, eLearning has a lot to offer the tutor and the students. The emergence of new and evolving technologies stands it in good stead to be innovative and creative. However there is the danger that the befits may not be fully realized if there is more focus on technology at the expense of promoting education and enhancing teaching and learning. It is imperative for the practitioners to use these technologies and define some standards for implementing efficient and effective teaching and learning. E-Learning is here to stay. Current trends in development and deployment makes it a driving force in business, industry and education. E-Learning is becoming part of organizational infrastructure existing as a strategic solution to be deployed throughout the organization aimed at increasing effectiveness, competency and improving relationships. The three main components of elearning are content, technology and services. There is the tendency to develop suites comprising solutions made up of components of each of these aimed at particular issues or training. There is an emerging trend involving blended learning designed to integrate e-learning with traditional training methods to enhance overall effectiveness. The challenge today is getting a sort of education in the world that will increasingly rely on the computer. In these times of rapid changes and globalization, an education that fails to do the great job of helping is people keep up with the pace of change will not survive the future $[11,12]$. Content creation online has changed dramatically, quite a good number of learners have their own virtual space where they create and share information. The problem of today is no longer finding information, but filtering and distributing it. In web collaboration, some of the information is taken, woven to create more information and then shared with others. Participation remains crucial and we see collaborators taking over from the experts leading to ground breaking innovation resulting from unparalleled access to like minded people around the world.

\section{REFERENCES}

[1] Ross M An Alternative Approach to an Honours Degree, IEE Engineering Education 2003, Southampton, ISSN number 09633308, 2003

[2] Ross M, Staples G, Udall M, Teaching Professional Issues using Activity Based Learning, Proc INSPIRE 2009, Southampton

[3] Protheroe H, Carrier T, Miller E, Rees J, Ross M, Blended Learning for Six Sigma, Proc SQM 2008,

[4] Norris S, Mann L, Real Life Second Life ${ }^{\circledR}$; Blurring the Teacher Learner Relationship, INSPIRE 2009

[5] Mason R, Models of Online Learning, 1998, available online at http://www.aln.org/alnweb/magazine/vol2_issue2/Masonfinal.htm , accesses 01/04.2010

[6] Iskander M F, Technology-based electromagnetic education, IEEE Trans Microw Theor Tech, vol. 50, No. 3, 2002, pp 1015-1020. http://dx.doi.org/10.1109/22.989985

[7] Brusilovsky P, Eklund J, Schwarz E, Web-based education for all: A tool for development adaptive courseware, Comput Netw ISDN Sys, vol. 30, No. 2, 1998, pp 291-300 http://dx.doi.org/10.1016/ $\underline{\mathrm{S} 0169-7552(98) 00082-8}$

[8] Kirschner P A, Paas F, Web-enhanced higher education: A tower of Babel, Comput Hum Behav vol. 17, No. No. 4, 2001, pp 347 35

[9] Kerrey B, Isakson J, The power of the Internet for learning: Moving from promise to practice, Web-based education commission, 185, 2000..

[10] Goeller K E, Web-based collaborative learning: A perspective on the future, Comput Netw ISDN Sys vol. 30, No. 6, 1998, pp 634635. http://dx.doi.org/10.1016/S0169-7552(98)00129-9

[11] Wlodkowski R J., Kasworm C E., Accelerated learning : Future roles and influences, New Directions for Adult and Continuing Education, vol. 2003, No. 97, 2003, pp 93 http://dx.doi.org/ 10.1002/ace.92

[12] Ya-Ching L (2006), An empirical investigation into factors influencing the adoption of an e-learning system, Onlilne Information Review, vol. 30, No. 5, 2005, pp 517

\section{AUTHORS}

J. O. Uhomoibhi is with the University of Ulster, Northern Ireland, BT37 0QB, UK. (e-mail: j.uhomoibhi@ulster.ac.uk). He is author for correspondence.

M. Ross is with the Southampton Solent University, Hampshire, SO14 0RD, UK, (email: margaret.ross@solent.ac.uk).

Received 13 December 2012. Published as resubmitted by the authors 18 March 2013. 